\title{
Is there a cardiodepressant effect of higher BMI on contractile force of skinned human fibers?
}

\author{
Constanze Bening ${ }^{*}$, Nicole Stumpf, Christian-Friedrich Vahl \\ From World Society of Cardiothoracic Surgeons 25th Anniversary Congress, Edinburgh \\ Edinburgh, UK. 19-22 September 2015
}

\section{Background/Introduction}

Body mass is reported to influence myocardial performance. Latest studies have emphasized the importance of negative inotropic Adipocyte-derived factors and assume an impact on cardiac contractile function. However the underlying mechanism remains unclear.

\section{Aims/Objectives}

Our hypothesis was if body mass and gender impact cardiac force development on the level of the contractile apparatus.

\section{Method}

Therefore we performed a study to examine the influence of BMI (3 groups: group I > 25, group II 25-30, group > 30 ) on the myocardial performance of skinned muscle fibers. Right atrial tissue preparations of 70 patients undergoing aortocoronary bypass operation (CABG, 48 patients, group a) and aortic valve replacement (AVR, 22 patients, group b) was obtained prior to cannulation and prepared for the experimental set up. The fibers were exposed to graduate increase of calcium concentration and the force values were recorded and stored by the associated computer program. The statistical analysis was performed with Pearsons's correlation (SPSS, $\mathrm{p}<0.05$ significant).

\section{Results}

1.) $\mathrm{BMI}>30$ (group III) was associated with less force (Mean force $1.58 \pm 0.1 \mathrm{mN}, \mathrm{p} 0.02$, $\max$ force $2.24 \pm 0.17$ $\mathrm{mN}, \mathrm{p} 0.02$ versus group II (Mean force $1.8 \pm 0.3 \mathrm{mN}, \mathrm{p}=$ 0.04 , max force $2.59 \pm 0.2 \mathrm{mN}, \mathrm{p} 0.03$ ) and group I (Mean force $1.8 \pm 0.1 \mathrm{mN}, \mathrm{p}=0,03$, max force $2.62 \pm 0.3 \mathrm{mN}$, $\mathrm{p}$ 0.03). The force values between group I and II were not significantly different. Dividing the groups after surgical procedure the impact of BMI on force development in

Department of Cardiothoracic and -Vascular Surgery, University Hospital Mainz, 55131, Mainz, Germany 